\title{
Emotional and behavioural barriers to learning and development in the inclusive education classrooms in South Africa : developing a training programme for teachers
}

Potgieter-Groot, L., Visser, M., Lubbe-de Beer, C

\begin{abstract}
$\underline{\text { Objective }}$

The interaction between teachers, classroom strategies and learners experiencing emotional and behavioural barriers to learning and development in a system of inclusive education, results in multiple dynamics on different levels. Because many teachers in main stream education lack training to deal with learners experiencing emotional and behavioural barriers, resistance towards inclusive education becomes evident. This paper describes the process of the development of an in-service training programme for teachers who deal with learners with emotional and behavioural barriers in their classrooms.

Method
\end{abstract}

A process of action research was used to allow the researcher, in collaboration with 47 teachers from 2 primary schools, to develop a training programme to address the specific needs of teachers in dealing with learners experiencing emotional and behavioural barriers in their classes. Qualitative feedback from teachers and observations by the researcher and external observers were used to evaluate the appropriateness of the training.

\section{Findings}

Teachers experienced that appropriate classroom management strategies made a significant difference in the behaviour of learners experiencing emotional and behavioural barriers. The 
training affected teachers' attitudes, teacher-learner interaction, learner behaviour and school organisation.

Conclusion

In-service training for teachers can impact on the effective implementation of inclusive education. This programme can be adapted to address the needs of teachers in other areas.

\section{Keywords:}

Inclusive education

Emotional and behavioural barriers

In-service training

Action research

Classroom strategies

As early as 1962 a group of researchers, educators and program developers started to question the practice of excluding learners with barriers to learning and development from the mainstream education (Walther-Thomas et al. 2000). Internationally more emphasis was placed on human rights, equal opportunities, independence and social integration of people with disabilities, such as learners with barriers to learning and development. This cumulated into the Salamanca declaration of 1994 that promoted inclusive education to combat discrimination against learners with barriers to learning and development and to create communities that are more open and welcoming to all (Moll and Drew 2006; UNESCO 1994). Important political and social changes with a strong focus on human rights took place in South Africa, such as the change to a democratic government, adoption of a new Constitution based on human rights and the promotion of education for all. These changes filtered into schools 
and classrooms (Oosthuizen 2006) in the form of inter alia a policy of inclusive education that is in line with democratic and human rights principles of the new dispensation (Engelbrecht, Oswald and Forlin 2006). Education White Paper 6 on Special Needs Education (Department of Education 2001) paved the way for one inclusive education system providing all learners with equal access to education. Inclusive education is a complex concept that can be interpreted differently and implemented in various ways. Inclusion in this context refers to developing education systems that create teaching practices and policies that promote the rights of learners who experience barriers to learning and development to attend mainstream schools (Moll and Drew 2006). It is based on the principles of "building a more democratic society, a more equitable and quality education system, and a belief that extends the responsibility of regular schools to accommodate the diverse learning needs of all learners" (Swart and Pettipher 2005: 4). In inclusive education teachers are expected to accommodate learners with a variety of barriers to learning and development in mainstream classrooms. The implementation of inclusive education highlighted teachers' limited training on strategies to support and manage learners with emotional and behavioural needs in the mainstream classroom setting (Lessing and Dreyer 2007).

Emotional and behavioural barriers of learners in South African schools are major concerns that require urgent attention (Mestry, Moloi and Mohamed 2007) because of the number of children affected and the negative impact they have on teaching and learning in mainstream schools. The Individuals with Disabilities Act (IDEA) define emotional and behavioural barriers as "a condition exhibiting one or more of the following characteristics over a long period of time that adversely affects a child's educational performance: (A) An inability to learn that cannot be explained by intellectual, sensory or health factors; (B) An inability to build and maintain satisfactory interpersonal relationships with peers and teachers; (C) 
Inappropriate types of behaviour or feelings under normal circumstances; (D) A general pervasive mood of unhappiness or depression; (E) A tendency to develop physical symptoms and fears associated with personal or school problems" (Kavale, Forness and Mostert 2005: 46; Hannell 2006: 37/8). This definition based on the work of Eli Bower includes child schizophrenia, selective mutism, aggression, oppositional behaviour and affective disorders such as depressions, phobias and fears (Mastropieri and Scruggs 2007). Other manifestations include socially maladaptive behaviours such as a disregard for the rights of others, and destructive and dishonest behaviour (Kavale et al. 2005).

A literature review revealed that emotional and behavioural barriers as described by the above mentioned viewpoints are found in between $3 \%$ to $6 \%$ of learners (Kauffman 2005) and that it is increasing globally (Winter 2007). Using these estimates, it means that there can be potentially 2 or more learners per class in South African schools that may experience emotional and behavioural barriers. If a broader definition of emotional and behavioural barriers is used that includes a systemic perspective, thereby taking into account the context of disadvantage in which many children grow up, this number of learners per class may even be much higher in South African schools.

Teachers are often not trained or equipped to deal with the variety of barriers to learning that learners may experience in an inclusive classroom environment (Prinsloo 2005). This requires urgent attention from policy makers, universities, teachers and all other stakeholders (Oosthuizen 2006), as teachers tend to spend too much time managing learner behaviour such as disruptive behaviour, aggression, vandalism, withdrawal and depression (Prinsloo 2005). This state of affairs leads to a general climate that jeopardises the teaching and learning process and teachers become frustrated, stressed and demotivated (Lessing and Dreyer 2007; Prinsloo 2005). Royer 
(2005) indicates that teachers are not equipped to use strategies that could support and accommodate learners with emotional and behavioural barriers. Teachers need to be empowered by either in-service or pre-service training to manage and accommodate the variety of learners in their classes (Harcombe 2009). Such training is not only necessary to support learners experiencing barriers to learning, but also to minimise the influence of their behaviour on the teaching and learning process (Oosthuizen 2006; Prinsloo 2005).

According to the medical model, emotional and behavioural needs are defined as disorders situated inside the individual (Ayers and Prytys 2002) which require clinical intervention, and in some cases placement in special schools (Green 2001). With the movement towards inclusive education, a systemic viewpoint was adopted which accepts that individual behaviour is a function of intrinsic and environmental factors. According to the bioecological model of Bronfenbrenner (2005), the individual is situated in different layers of social relationships of which the home, school, classroom and peer group form just a few. The model focuses on the interactive mutual influences of the various systems involved (Dalton, Elias and Wandersman 2007). Emotional and behavioural barriers are accordingly seen as consequences of dynamic interaction between biological, individual and social systems (Farrell 2006). "Therefore, within the ecological model, behaviour is viewed as 'disturbing' rather than inherently 'disturbed,' and emphasis is placed not only on the child but also on the interaction with factors in the child's ecosystem" (Coleman and Webber 2002: 135). Using a systemic framework thus requires changes in teachers' behaviour, classroom practices and school organisation to be able to take active steps and being supportive of the diversity of learner needs (Harcombe 2009). This approach also leaves space for utilising knowledge gained from 
the medical model to facilitate understanding of specific barriers in learning and the support that learners need (Clough et al. 2005).

This paper describes the development of an in-service training programme to enhance teachers' abilities to work with learners experiencing emotional and behavioural barriers in an inclusive education environment in South Africa. The paper highlights some of the dilemmas of teachers as well as the strategies they found to be effective in the classroom to deal with learners experiencing barriers to learning.

\section{Research methods}

Action research was used in the development of the programme because of its development philosophy and emphasis on the utilisation of local knowledge (Somekh and Zeichner 2009). Action research is an orientation to inquiry rather than a methodology in itself. The process often starts with a question on how a situation that is significant to all participants can be improved and is driven by personal commitment to contribute to human flourishing (Reason and Bradbury 2008b). Action research seeks to create participation and to engage all stakeholders as agents of transformation, rather than passive research subjects (Reason and Bradbury 2008a, Swantz 2008). In this case the wealth of knowledge and commitment in the teaching community was used to facilitate change. Action research is therefore the process of solving practical problems through participation of those involved in the situation. The researcher becomes a facilitator of this process and the participants act as co-researchers (Swantz 2008).

Action research typically implies systematic cycles of action that involve evaluation, planning, action/intervention and reflection/evaluation (Armstrong and Moore 2004). During the action phase participants as co-researchers test practises and gather evidence. In the 
reflection phase evidence is considered and plans are made for future actions (Reason and Bradbury 2008a). Action research is thus a form of applied research that is action based, where the roles of the researcher and researched are interchangeable in order to develop interventions specific to the needs in a context (Swantz 2008).

\section{Context of the research}

The research was conducted during 2008 and 2009 in two mainstream primary schools (providing education from foundational to senior phase - Grade 1 to 7 ) in the Johannesburg South education district. Initially four schools were selected to participate in the research. They were purposely selected in collaboration with staff at the Johannesburg South Education District Office using two criteria: (i) schools that most needed training for teachers to deal with learners experiencing emotional and behaviour barriers, as indicated in the schools' development plans submitted to the district office in 2008; and (ii) schools that accommodate learners from a diversity of backgrounds. Purposeful sampling was used, as background information about schools was used in the selection (Babbie 2008). Two of the schools did not participate in the research: one school was not interested and the other school started but withdrew later because of non-related internal conflict.

Two schools participated in the research. One school is situated in a low socioeconomic community and also provides education to learners from a nearby informal settlement (very low socio-economic community). Learners who attend this school grow up in severe poverty as a consequence of high unemployment levels. The second school is situated in the southern suburbs of Johannesburg in a middle-class environment. About $70 \%$ of the learners from this school come from a middle class background, while $30 \%$ are either immigrants from other African countries or children that commute from the lower socio- 
economic neighbouring communities in Soweto. In both school communities social ills like drug abuse and family disintegration are high.

\section{Role-players/participants}

The researcher as an educational official in the Department of Education acted as participant, observer and facilitator during the needs assessment and the intervention. The researcher was assisted by two external observers (both education psychologists) who provided input and notes on observations during the intervention sessions. Forty nine (49) teachers from the two schools volunteered to participate in the research. Forty seven participants attended all three sessions, while two attended only the first session. If someone could not attend a session at their own school, they would attend it at the other school. The majority of the participants (81\%) were females (as females are more commonly employed in primary education). Most of the participants $(72 \%)$ were teachers, while $28 \%$ formed part of different management structures at the schools.

\section{The research process}

Ethical approval and permission to conduct the study was obtained from the Ethics Committee of the Humanities Faculty of the University of Pretoria and the Gauteng Education Department. The school management of the schools involved also agreed that teachers could voluntarily participate in the research. After the principals and school governing bodies of the identified schools agreed to the research, the researcher visited the schools. Teachers were informed about the research and invited to participate voluntarily. Forty nine teachers volunteered and gave informed consent. The action research process started with a needs assessment at each of the two schools. Data was collected through four focus group discussions involving the 
teachers from the two schools. Open-ended exploratory questions were asked about the behaviour of learners in their classes, class management strategies they employ and their need for training to deal with learners with barriers to learning. The focus group discussions were tape-recorded, transcribed and analysed using thematic analysis (Braun and Clarke 2006). The needs of teachers were identified and are given as part of the results section.

Using the results of the needs assessment and a thorough literature study on evidencebased strategies to deal with learners experiencing emotional and behaviour barriers, the initial three-session intervention was developed as in-service training for teachers. The schools made only three two-hour sessions available for this intervention. This programme included school and classroom practices that embrace inclusive practices that are learner-paced to facilitate a good fit between the learner, the classroom environment and the level of learning material (Moll and Drew 2006) and foster positive teacher-learner relationships (Prinsloo 2005; Sutherland et al. 2008). Specific focus was placed on classroom structure and management, rules and set routines that provide consistency, safety and security for all learners (Hyam 2007; Kewley 2005; Prinsloo 2005; Prosser 2006; Vaughn, Bos and Schumm 2000). For example, techniques were discussed how to structure specific activities such as how learners should enter the class, what they should do while waiting for the lesson to start, how they should ask for support, how to hand in their books, when they should write down homework, how learners should be seated and how they should clean up classes at the end of the period. A prominent feature was on presenting the curriculum to enhance meaningful learning through inter alia switching between mental and physical activities; varying the level of difficulty to ensure the experience of success (Prosser 2006); following a set lesson plan; giving short instructions; teaching one concept at a time (Alban-Metcalfe and Alban-Metcalfe 2001; Hannell 2006). Other more specific strategies included the use of behaviour-modification strategies 
such as positive reinforcement as part of a token economy program (Farrell 2006; Raymond 2008); different forms of time-out (Farrell 2006); detention (Oosthuizen 2006); and restorative justice (Prinsloo 2005). Strategies to enhance positive behaviour included self-regulation (Farrell 2006); goal setting (Canter and Canter 2000); self-instruction (LeBlanc, Le and Carpenter 2000); self-monitoring (Farrell 2006); and self-reinforcement (Farrell 2006; Hannell 2006).

\section{Implementation and data collection}

The researcher presented the three-session programme bi-weekly in one school and once a term in the other school (as preferred by the specific school). Two external observers were present to observe the intervention process and to provide feedback. After each session, the teachers had to implement what they had learned and had to report on these experiences in feedback forms and during the next session. Each session commenced with teachers' verbal feedback on their experiences during and after the previous session.

Data on the appropriateness and influence of the strategies that teachers found to be effective in their classes was gathered by means of various forms of qualitative data. Data was obtained from the feedback forms that the participants completed after each session as well as the researcher's notes and the external observers' notes made during and after each session.

In action research data interpretation takes place throughout the research process. This enabled the researcher to make adjustments to the intervention as the needs of the educators became apparent during the process (Armstrong and Moore 2004; Holly, Arhar and Kasten 2005). Feedback from the first and second sessions could therefore be incorporated into the next session to address the specific needs of the participants. For example, the session on the characteristics, causes and specific strategies to deal with specific conditions was not part 
of the original planning but was added because of feedback received from the teachers. The work of Alban-Metcalfe and Alban-Metcalfe (2001), Bester (2006), Hannell (2006) and LeBlanc et al. (2000) was used for this session. The focus was on teacher-learner relationships and how school management style can be proactive in curbing negative behaviour and providing a supportive environment for teachers and learners and how to use advance strategies like behaviour modification, token economy programmes, different types of punishment and foster learner accountability and self-regulation. The programme content presented in Table 1 was the actual intervention programme presented after all the adjustments were made as the research process unfolded.

\section{Table 1 Content of the intervention presented}

\begin{tabular}{|c|c|c|}
\hline Session 1 & Session 2 & Session 3 \\
\hline $\begin{array}{l}\text { What are emotional and } \\
\text { behavioural needs? } \\
\text { Inclusive Education } \\
\text { Systems theory } \\
\text { Classroom practices to minimise the } \\
\text { impact of emotional and behavioural } \\
\text { needs } \\
\text { - Teacher learner relationship } \\
\text { - Classroom rules and routines } \\
\text { - Classroom organisation } \\
\text { - Lesson planning and presentation } \\
\text { - Strategies to encourage task } \\
\text { behaviour } \\
\text { - Exploring the role of participants in } \\
\text { action research }\end{array}$ & $\begin{array}{l}\text { Characteristics, causes and } \\
\text { specific strategies to deal } \\
\text { with: } \\
\text { Attention Hyperactivity } \\
\text { disorder } \\
\text { Oppositional defiance } \\
\text { Conduct disorder } \\
\text { Depression } \\
\text { Anxiety Disorder }\end{array}$ & $\begin{array}{l}\text { Teacher/parent relationship } \\
\text { School management aspects } \\
\text { How can teachers lighten their burden regarding } \\
\text { learners with emotional and behavioural needs } \\
\text { More advance strategies: } \\
\text { - Behaviour modification } \\
\text { - Token economy } \\
\text { - Time-out } \\
\text { - Positive reinforcement } \\
\text { - Negative reinforcement } \\
\text { - Detention } \\
\text { - Restorative discipline } \\
\text { - Self monitoring } \\
\text { - Self instruction } \\
\text { - Goal setting } \\
\text { Teaching of specific skills to learners: } \\
\text { - Problem solving skills } \\
\text { - Social skills } \\
\text { - Relaxation training } \\
\text { - Self talk } \\
\text { Information on prescribed medication used }\end{array}$ \\
\hline
\end{tabular}




\section{Data analysis}

Qualitative data analysis was used to capture the perceptions and experiences of the participants, and to make sense of the large volume of data by restructuring and reducing the information (Miles and Huberman 1994). Data from the reports of the researcher, observers and participants was analysed separately and eventually integrated in a process of triangulation. Categories were first coded using open coding, and then combined and interpreted in terms of themes. Patterns were identified from the different themes and also from the changes that occurred (Braun and Clarke 2006; Schwandt 2007). The systems theory was used as theoretical framework (Bronfenbrenner 2005) to understand the experiences and changes that took place on different levels of the educational system. The presentation of the themes and patterns is organised in terms of the different systems levels. Emphasis was placed in the quality of data analysis. This was done by having more than one researcher who interpreted the data and using the cyclic process of action research to verify the interpretation of the experiences of teachers in their classrooms.

\section{Findings}

\section{Needs analysis}

The findings of the needs analysis are structured in terms of three broad themes, namely learner behaviour in class, teachers' intervention strategies and training needs.

Learner behaviour in class

Almost all the teachers indicated that they had numerous learners in their classes who experience emotional and behavioural barriers to learning. The behaviour of this group of learners varied from being disorganised to being involved in serious incidents of anger and 
aggression. The teachers' description of learner behaviour can be categorised under the following sub-themes:

Anger and aggression are common and often directed towards inanimate objects like desks or books, or at fellow learners or teachers, often without any reason. Some teachers said: "These learners are often aggressive, angry and destructive, everybody just try to keep out of their way."; "They think that smacking and bulling is the only solution to each and every problem."

Disruptive behaviour often upsets the teacher because valuable teaching time is wasted and it hampers the progress of other learners. Teachers' frustration is expressed as follows: "I spend hours of valuable teaching time just trying to get the disruptive students under control to get some schoolwork done. They disrupt the whole class."

Challenge authority: Some learners show an apparent lack of self-control and tend to challenge authority, as illustrated in the following quotes: "They are disobedient, unruly and threaten the teacher with the police"; "They throw things at teachers."

Attention-seeking behaviour: Learners exhibit a variety of inappropriate ways of attention seeking that challenge the norms and standards of society and disrupt classes. For example: "He throws himself on the ground and starts to wail"; "He will urinate in front of everybody knowing well that a teacher can see him."

Disorganised schoolwork: Learners often have a tendency to lose or forget things such as books, shoes and writing material. They will forget to attend classes or to write down homework. They are inattentive, daydream, have academic backlogs, are unmotivated and lack attention. The teachers described them as follows: "They refuse to pay attention to what is being taught."; "They complete work in a haphazard manner." 
Intense emotional reactions: A few teachers were concerned about inappropriate emotional reactions of some learners such as apathy, withdrawal and oversensitivity as illustrated by the following: "Many pupils display a great deal of apathy"; "The boy is very emotional, whenever the word 'mother' is mentioned he starts to cry", "He fights for no reason, other learners can't even look at him",. "In my class there is a learner, who if I reprimand the class, she would cry as if everything was just focused on her."

Teachers emphasised that emotional and behavioural needs of learners are often the result of family and environmental factors such as being from a child-headed family or growing up in an abusive family. One teacher summarised it as follows: "Major behaviour problems mainly stem from emotional, social and domestic problems. The situation at home plays a major role in their school work."

\section{Teachers' intervention strategies}

It seems to be difficult for teachers to instil order in classes of 40 or more learners, especially when it seems as though some learners experience emotional and behavioural barriers to learning. Teachers' reactions varied from withdrawal and feeling incompetent, to being proud of supporting and making a difference in learners' lives.

The following statements illustrate the teachers' level of frustration, insecurity and emotional exhaustion when dealing with learners with emotional and behavioural barriers: "They exhausted me mentally and physically. We can't cope, these children should go somewhere when they are young, and get it sorted before they release them into mainstream"; "I would have cracked up if it wasn't for the support of my colleagues." In many cases teachers indicated that learners who experience emotional and behaviour barriers are a burden and should not be part of mainstream schools: "This is not my job. I am a trained 
teacher and I am not qualified to identify and deal with problems of an emotional nature." Many of the teachers did not know how to deal with learners' problem behaviour and often send them out of the class or to the principal's office.

On the other hand, a few teachers used good practices to deal with learners' differential needs, such as giving individual attention, providing security through a fixed routine and to reinforce positive behaviour. These teachers wanted to assist learners and said: "It makes me feel proud if I can support a learner with special needs."

\section{Training needs}

All teachers involved in this research expressed a need for training and support in dealing with learners experiencing emotional and behavioural barriers, because they had no previous training to deal with the situation. The majority of teachers felt incompetent to deal with the diverse needs of learners. Some teachers lacked knowledge and understanding of emotional and behavioural barriers to learning as indicated in the following statements: "Aren't there something like kids who are naughty because of sugar intake?"; "At times we need to speak to parents regarding the needs of their child but I do not really know what to say if it comes to things like $A D D$ and $A D H D . "$

Some teachers wanted to make a difference but needed strategies and guidance in doing so: "I would love to develop a greater sensitivity to those learners' needs and to be able to assist them to enjoy learning, become responsible, achieve more and make correct decisions." 


\section{Feedback after implementation of the intervention}

Themes from the different data sources were integrated into broad themes. The impact of the intervention was interpreted according to various systemic levels. Action research is a dynamic process allowing all participants to learn, including the researcher.

\section{New knowledge gained through participation}

The open participatory format of the intervention and the action research approach allowed for open discussion during the sessions where teachers could express their needs and experiences. Especially in the second and third session all participants shared their experiences, which contributed to knowledge of possible successful strategies or how to adapt strategies to be applicable in their situation. This resulted in flexibility in the development of the intervention. Needs expressed during the first sessions could therefore be built into the training in the following sessions. For example, to address teachers' limited knowledge of emotional and behavioural needs, specific information was added to the second session. Sharing experiences also motivated other teachers to experiment with new strategies in their classes. This fostered a communal sense of participation in the implementation of knowledge gained.

The teachers' reaction to the content of each of the sessions will be outlined briefly. After the first session teachers indicated that information on classroom practices, planning strategies, teacher-learner relationship and how to encourage learners were usable strategies. The teachers responded: "These are the kind of things that just go missing in classes, but are so important."; "I am three years from retirement, why could someone not spell this out to me earlier in my teaching career?"

During the second session the information on emotional and behavioural barriers succeeded in providing and enhancing teachers' understanding of learners with emotional 
needs. Because none of the teachers had formal training in how to support learners experiencing behavioural needs, the basic information was an eye-opener for them: "This is a new world to me."; "Now I do understand why he can never finish his work on his own." It appears that teachers in the inclusive environment benefited from basic information provided in the session. Basic knowledge served to improve the teaching and learning environment for both learners and teachers. The teachers became aware of the impact of the class and school environment and different disciplining strategies on the learners' behaviour.

Strategies to support learners with emotional and behavioural needs were discussed in the third session. Although some of these strategies were new to teachers, some of the teachers showed interest to understand how to implement strategies such as problem solving, relaxation exercises and social skills training. Real classroom examples were helpful. Teachers' feedback indicated that some of them implemented these strategies and described it as successful, as shown in the following quotes: "I introduced him to social skills like making friends and being a friend." "I taught my whole class through role play how to handle teasing."

Some of the teachers reacted with resistance because they regarded some strategies such as behaviour modification, relaxation, goal setting and social skills training as too advanced and complicated and not part of their roles as teachers. They reacted with statements such as: "For this we need at least one extra free period per day."; "We are teachers, not psychologists."

The teachers had a long discussion about how to implement alternative forms of punishment. They agreed that if detention sessions were shortened or held during break time, it could be more attainable. Restorative justice was difficult to implement because children did not have money to replace stolen or broken items. Teachers agreed that learners had to take responsibility and face the consequences for their transgressions, even if it meant picking up 
litter during break. The principles of time-out were explained to teachers since they were not familiar with the different kinds of time-out; learners were only sent out of the class because of the teachers' own experience of frustration.

The fact that the drop-out rate of the participants during the intervention was very low (2 out of 49), is perhaps indicative of the value of this intervention. The fact that other teachers, heads of departments and principals as well as teachers of other schools wanted to join the training, also showed that teachers valued the intervention.

\section{Changes in teachers' perspectives}

Teachers' knowledge and understanding of learners' needs improved as illustrated in the following quotes: : “I am in a better position to understand my learner's needs and behavioural patterns. It makes it easier to understand why they behave in certain ways." Teachers felt empowered and competent with a whole repertoire of ways to support and teach learners: "It guided me to develop different ways to handle learners with behaviour needs. I feel confident in dealing with such needs, however I need more experience and practice."

New knowledge and skills contributed to teachers' changed attitude towards learners experiencing emotional and behavioural barriers. Teachers who had previously expressed strong views against inclusion now discussed ways of dealing with learners' needs: "I kind of empathised with the learners, and try to understand better where they are coming from."; "I changed my attitude towards these learners and started to listen to them." It was evident that as the teachers become more empathetic and caring, they developed a willingness to build trusting and caring relationships with these learners: "I now understand it is really hard for some learners." "I talk to learners one-on-one to develop trust. There's an open door for learners to speak." 
Teachers did not only gain knowledge and changed their attitudes, they also implemented various strategies to improve classroom management and to deal with specific needs of learners. They reported how new strategies such as giving short, focused instructions, keeping activities short, using rewards, giving responsibilities, standing next to the learner who disrupts while giving instructions, providing peer assistance and not reprimanding learners in front of their peers, helped them in managing their classes. One teacher reported: "I established appropriate, consistent classroom routines and rules. I changed to your suggestions regarding classroom management, placement of learners and being more of a hands-on teacher." Teachers also showed interest in using more advanced strategies like social skills training, behaviour modification and token economy programs to support learners: "I taught my whole class through role play how to handle teasing"; "Having a good response with positive reinforcement, I have recently introduced little toys for showing positive behaviour over time."

Teachers used strategies appropriately, adapted strategies where necessary, and became more creative in devising their own strategies to suit their specific environment. For example, a teacher created his own story of "Positive Peter and Negative Nick" to serve as inspiration for learners from disadvantaged backgrounds. Another teacher gave "Smarties" (multi-coloured candy) as positive reward and coined the phrase: "Smart kids get Smarties." Another teacher made use of the "stick method" to increase classroom participation. (A stick is passed on in class; the one who receives the stick has to say something). One teacher made puppets out of cheap paper bags to support shy learners to get involved. These strategies can be seen as teachers' inspiration to interact more effectively with learners.

The teachers were proud and inspired by what they had achieved in class. They now felt more confident to talk to parents regarding the needs of children and knew to whom they could 
refer learners experiencing intense emotional and behavioural barriers. Some teachers felt so confident that they supported their colleagues from other schools.

At the end of the program educators were requested to indicate their level of competency in supporting learners experiencing emotional and behavioural barriers on a five-point scale. The average score of teachers was 4 out of 5, which indicated they now evaluated themselves as very competent to support learners experiencing emotional and behavioural barriers. . Changes in learners' behaviour

The teachers observed changes in learner behaviour as a result of the new strategies they employed in class. Teachers mentioned that they observed improvement in the learners' academic work and a willingness to try: "It's actually pleasing to see learners now trying, where they previously just disrupted the lessons"; "I see improvement in the work and behaviour of some learners." Teachers described how changes in the classroom strategies benefited all the learners. The learners seemed to be more motivated and disciplined and the class atmosphere was less stressed. One teacher explained it as follows: "I feel there is less stress in the class if she receives a little more attention and performs little tasks. She also seems to be more relaxed, therefore I don't have to contemplate what problems she will cause and how I will deal with it."

A more trusting relationship between teachers and learners developed where teachers listened to learners. This resulted in more positive behaviour amongst learners as illustrated by the following quotes: "Currently he comes regularly to class and will give me a huge smile or a hug", "He is more confident now. It's actually quite pleasing to see him come out of his shell."

The change in class atmosphere could possibly be seen as the product of changes around classroom management, planning and supportive strategies for learners with emotional and 
behavioural needs. This indicates a better fit between learners and tasks, class and school. More time could be spent on teaching and learning, and less on disciplining learners.

\section{Changes in the school environment}

In one of the schools, where all the teachers were involved in the intervention, the teachers started a working group to develop specific support plans for each learner experiencing barriers to learning. When all teachers followed these plans it ensured consistent treatment of the learners which provided a safety net for learners. This whole-school approach enabled the teachers to implement their new knowledge. In this school change was more rapid and visible, even to outsiders, than in the school where individual teachers implemented new classroom strategies in isolation. Still, it was found that one competent and dedicated teacher can effect change in a learner's life while supporting other teachers to deal with learners' behaviour.

Changes in the relationship between the school and parents

After the intervention the teachers felt more equipped to support and guide parents. This resulted in an increase in co-operation between parents and teachers to find the best possible options in order to address the needs of the learners. Teachers mentioned that they witnessed how relationships between parents and children were improving. One teacher stated that she had observed a parent who fetched her child from school earlier in the afternoon, whereas previously the child was left unattended for hours after school.

Change in the larger education system

The teachers who attended the intervention talked to colleagues at other schools and offered support to them. One teacher expressed her feeling of empowerment as follows: "My knowledge is now at a level whereby I can also help other teachers with strategies that they 
can apply in their classrooms and schools." This communication between schools led to more teachers wanting to be part of the intervention, though the limited space in the venues did not allow for larger groups.

The unintended cross attendance of teachers between the two schools in which the research was conducted, seemed to be beneficial because teachers shared their experiences and motivated teachers of the other school to implement various strategies they found effective in their school. In both the schools positive changes were visible and teachers and principals talked about it. This resulted in a formal request from the educational authorities to extend the training to other schools in the area.

\section{Conclusion}

This research clearly indicated that teachers required specific knowledge and skills to manage classroom behaviour and to engage learners in academic tasks, especially in a context of inclusive education with learners who have diverse needs. This confirms the views of Preciado, Horner and Scott (2009) and Sutherland et al. (2008). Most of the teachers who participated in this research had no previous training in dealing with learners experiencing emotional and behavioural barriers to learning. They felt incompetent to address the diversity of learners' needs. Most of the teachers experienced emotional and behavioural needs as threatening and reported some form of burnout. They also reported that they had received no support from educational authorities to deal with learners' behaviour. As a result teachers tended to feel overwhelmed and negative about the implementation of inclusive education. Lessing and Dreyer (2007) had similar findings that teachers felt overwhelmed and consequently wanted to leave the education profession. 
This research demonstrated that a short-term three-session intervention that provides basic knowledge and strategies to deal with learner behaviour could be valuable as in-service training for experienced teachers with no specific previous training in dealing with learners experiencing emotional and behavioural barriers to learning. The intervention raised teachers' awareness of the needs of learners. More knowledge and understanding of the needs of learners helped teachers to change their attitudes towards learners and to build supportive relationships with them. Teachers became aware of the influence of the environment on the behaviour of learners, as well as their own behaviour in class. They started to experiment with different classroom management strategies which resulted in more learners displaying an increase in positive behaviour.

Changes in the teachers' knowledge and attitude and the experience of competence resulted in various changes in the school system. This supports the assumption that teaching and supporting strategies applied by teachers are co-determining factors for learner behaviour. The intervention helped the teachers to embrace the system of inclusive education as they felt less threatened by the new system.

The fact that this intervention was initiated from inside the Department of Education by District Officials enhanced the sustainability of the intervention because the researcher will remain part of the support network of the schools. This intervention can therefore be strengthened over time.

Of specific value in this research was the use of the action research approach, which helped the researcher to learn from the experiences of the teachers in the classroom. It involved the teachers as part of the research process to take responsibility in identifying strategies appropriate for their specific classes. The teachers were very creative and devised 
tailor-made strategies specific for their own environment, and displayed a willingness to share new expertise to support their fellow teachers. Feelings of empowerment seemed to have a positive effect on the teacher-learner relationship.

Although the intervention focused on the teachers as entry point in the school system, changes spread throughout various other systemic levels such as the teacher-learner relationship, class interaction, school organisation, and relationship with the parents. The close link between the theoretical framework and action research as methodology made it possible to study the implications of the intervention in broader systems. Teacher intervention is thus a powerful intervention level as teachers play an important role to create a better fit between the learner experiencing emotional and behavioural barriers and the broader systems.

Several limitations of the study need to be highlighted. The research involved a small group of teachers in one educational district and did not include schools of all different backgrounds which could limit the generalisation of the findings. The programme developed in this research can be used as a basic structure for further implementation but will be revised according to the experiences of teachers in the target schools. Additionally the research is based on the subjective reports of participants and does not include school performance data that could evaluate the influence of the intervention on learner achievement as well as sustainability of the results. This could be the focus of further evaluation of the intervention. The intervention, which was presented in three two-hour sessions, was actually too short to deal with the vast amount of relevant information. It is recommended that more time should be available for this programme to be effective in schools. Four two-hour sessions would seem more appropriate. 
The system of inclusive education is implemented in South African schools as a strategy to provide all learners with equal access to education - admits criticism that the needs of all learners cannot be addressed through such a system (Walther-Thomas et al. 2000). Critique against inclusion of especially learners experiencing emotional and behaviour barriers include that these learners forfeit their right to specialised interventions (Walther-Thomas, et al., 2000), that their behaviour can have a negative effect on the learning environment (AlbanMetcalfe and Alban-Metcalfe, 2001) and that inclusion may lower the quality of education (Walther-Thomas, et al., 2000). Although not the perfect solution to the critique and problems involved, this research indicates that specialised training of teachers is an essential prerequisite to enable the effective implementation of inclusive education. In-service training and support of teachers in South African schools is therefore of the utmost importance to deal with the diversity of needs of learners within inclusive education. It is recommended that interventions focus on all staff of a specific school, therefore following a whole-school approach, where the principal, school management, and individual teachers support the approach. The programme developed in this research can be used as a basic framework for an intervention to be implemented in other areas. Using an action research approach can promote participation of teachers to identify specific strategies relevant to address problems in their specific classes. In this way context-specific problems can be addressed and at the same time a more globally relevant intervention can be developed that could be applied in various contexts. 


\section{References}

Alban-Metcalfe J, Alban-Metcalfe J. 2001. Managing attention deficit/hyperactivity disorder in the inclusive classroom: Practical strategies for teachers. London: David Fulton.

Armstrong F, Moore M. 2004. Action research for inclusive education. London: Routledge Falmer.

Ayers H, Prytys C. 2002. An A to Z practical guide to emotional and behavioural difficulties. London: David Fulton.

Babbie E. 2008. The basics of social research (4th ed.). Belmont: Thomson Wadsworth.

Bester H. 2006. How to cope with AD/HD.A South African guide for parents, teachers and therapists. Cape Town: Human and Rousseau.

Braun V, Clarke V. 2006. Using thematic analysis in Psychology.Qualitative research in Psychology 3: 77-101.

Bronfenbrenner U. (Ed.). 2005. Making human beings human. Bio-ecological perspectives on human development. London: Sage.

Canter L, Canter M. 2001. Assertive discipline: Positive behaviour management for today's classroom. Los Angeles: Canter and Associates.

Coleman MC, Webber J. 2002. Emotional and behavioural disorders: Theory and practice ( $4^{\text {th }}$ ed.). Boston: Allyn and Bacon.

Clough P, Garner P, Pardeck JT, Yuen F. 2005. Themes and dimensions of EBD: A conceptual overview. In Clough P, Garner P, Pardeck JT, Yuen F (Eds.). Handbook of emotional and behavioural difficulties (pp 3-29). London: Sage.

Dalton JH, Elias MJ, Wandersman A. 2007.Community psychology: Linking individuals and communities ( $2^{\text {nd }} E d$.). Belmont: Thomson Wadsworth. 
Department of Education.2001. Education White Paper 6: Special Needs Education: Building an inclusive education and training system: July 2001. Pretoria: Government Printers.

Engelbrecht P, Oswald M, Forlin C. 2006. Promoting the implementation of inclusive education in primary schools in South Africa. British Journal of Special Education 33 (3):121-129.

Farrel M. 2006. The effective teacher's guide to behavioural, emotional and social difficulties. London: Routledge.

Green L. 2001. Theoretical and contextual background. In Engelbrecht P, Green L (Eds.) Promoting learner development: Preventing and working with barriers to learning (pp3-16). Pretoria: Van Schaik.

Hannell G. 2006. Identifying children with special needs: Checklists and action plans for teachers. Thousand Oaks, CA: Sage.

Harcombe E. 2009. Inclusive practices and learning diversity. In A Decaires-Wagner, H Picton (Eds.) Teaching and ADHD in the Southern African Classroom (pp 64-69). Northlands: Macmillan.

Holly ML, Arhar J, Kasten W. 2005. Action research for teachers: Traveling the yellow brick road $\left(2^{\text {nd }} E d\right.$.). New Jersey: Pearson Education.

Hyam M. 2007. Tips on how to cope with Attention Deficit Hyperactivity Disorder in the classroom. ADASA Conference September 2007. Johannesburg: Wits.

Kauffman JM. 2005. Characteristics of emotional and behavioral disorders of children and youth ( $8^{\text {th }} \mathrm{Ed}$.). New Jersey: Merrill/Prentice Hall.

Kavale KA, Forness SR, Mostert MP. 2005. Defining Emotional or Behavioural Disorders: The Quest for Affirmation. In Clough P, Garner P, Pardeck JT, Yuen F. 
(Eds.). Handbook of Emotional and Behavioural Difficulties (pp 45-58). London: Sage.

Kewley G. 2005. Attention Deficit Hyperactivity Disorder: What can teachers do? $\left(2^{\text {nd }}\right.$ ed.). London: David Fulton.

LeBlanc LA, Le L, Carpenter M. 2000. Behavioural treatment.In Hersen M, AmmermanRT. (Eds.). Advanced abnormal child psychology. $\left(2^{\text {nd }} E d.\right) .(p p$ 197218).London: Lawrence Erlbaum Associates (LEA).

Lessing AC, Dreyer J. 2007. Every teacher's dream: Discipline is no longer a problem in South African schools! In Oosthuizen IJ, Rossouw JP, Russo CJ, Van der Walt JL, Wolhuter CC. (Eds.). Perspectives on learner conduct (pp 120-131). Proceedings of the International conference on learner discipline. Potchefstroom, 2-4 April 2007.

Mastropieri MA, Scruggs TE. 2007. The inclusive classroom: Strategies for effective instruction. New Jersey: Pearson/Merril Prentice Hall.

Mestry R, Moloi KC, Mohammed A. 2007. The efficacy of a zero-tolerance approach to managing learner discipline. In Oosthuizen IJ, Rossouw JP, Russo CJ, van der Walt JL, Wolhuter CC. (Eds.). Perspectives on Learner Conduct: Proceedings of the first International Conference on Learner Discipline at the North-West University, Potchefstroom 2-4 April 2007(pp179-195).

Miles MB, Huberman AM. 1994. Qualitative data analysis, an expanded sourcebook $\left(2^{\text {nd }}\right.$ Ed.). Thousand Oaks, CA: Sage.

Moll I, Drew S. (Eds.) 2006. Implementing White Paper 6 screening, identification, assessment and support: Participant's manual.Wits: Sisonke Consortium on behalf of Department of Education. 
Oosthuizen IJ. 2006. Praktiese wenke vir leerderdissipline (Practical advice for learner discipline) Pretoria: Van Schaik.

Preciado JA, Horner RH, Scott KB. 2009. Using a function-based approach to decrease problem behaviours and increase academic engagement for Latino English language learners. The Journal of Special Education 42(4): 227-240.

Prinsloo E. 2005. Addressing challenging behaviour in the classroom. In Landsberg, E. (Ed.) Addressing barriers to learning: A South African perspective (pp. 449-465). Pretoria: Van Schaik.

Prosser B. 2006. ADHD Who's failing who? Sydney: Finch.

Raymond EB. 2008. Learners with mild disabilities: A characteristic approach. Boston: Pearson.

Reason P, Bradbury H. 2008a. Introduction. In Reason P, Bradbury H. (Eds.). The SAGE Handbook of Action Research: Participative Inquiry and Practice (2 ${ }^{\text {nd }}$ Ed.) (pp. 110). London: Sage.

Reason P, Bradbury H. 2008b.Groundings. In Reason P, Bradbury H (Eds.) The SAGE Handbook of Action Research: Participative Inquiry and Practice (2 $2^{\text {nd }}$ Ed.) (pp. 1113). London: Sage.

Royer E. 2005.The gap between research and practice. In Clough P, Garner P, Pardeck JT, Yuen F. (Eds.). Handbook of emotional and behavioural difficulties (pp. 373384). London: Sage.

Somekh B, Zeichner K. 2009. Action research for educational reform: Remodelling action research theories and practices in local contexts. Educational action research 17(1): 5-21. 
Sutherland KS, Lewis-Palmer T, Stichter J, Morgan PL. 2008. Examining the influence of teacher behaviour and classroom context on the behavioural and academic outcomes for students with emotional to behavioural disorders. The journal of special education 41(4): 223-233.

Schwandt TA. 2007. The SAGE dictionary of qualitative inquiry ( $3^{\text {rd }} E d$.) Thousand Oaks CA: Sage.

Swantz MJ. 2008. Participatory action research as practice. In Reason P, Bradbury H. (Eds.) The SAGE Handbook of Action Research: Participative Inquiry and Practice (2 $\left.2^{\text {nd }} E d.\right)(p p .31-48)$. London: Sage.

Swart E, Pettipher R. 2005. A framework for understanding inclusion. In Landsberg E, Krüger D, Nel N. (Eds.).Addressing Barriers to Learning; A South African perspective (pp. 3 -23). Pretoria: Van Schaik.

UNESCO. 1994. The Salamanca statement and framework on special needs education.Adopted at the World Conference on special needs education, Salamanca, Spain, 7-10 June 1994.

United Nations Convention on the Rights of Persons with Disabilities. 2007. Retrieved May 13, 2010, from the World Wide Web: http://www.un.org/disabilities.asp?navid=12\&pid+150.

Vaughn S, Bos CS, Schumm J. 2000. Teaching exceptional, diverse and at risk students in general education classrooms. New York: Pearson Education Company.

Walther-Thomas C, Korinek L, McLaughlin VL, Williams BT. 2000. Collaboration for inclusive education: Developing successful programs. Boston: Allyn and Bacon.

Winter SM. 2007. Inclusive early childhood education: A collaborative approach. Pearson: New Jersey. 